\title{
CULTURAL HERITAGE AND FLOODS RISK PREPAREDNESS
}

\author{
Klára Nedvědová ${ }^{\mathrm{a},}$, , Robert Pergl ${ }^{\mathrm{b}}$ \\ a Institute of Theoretical and Applied Mechanics, AS CR v.v.i., Prosecká 809/76, 19000 Praha 9; CZ - \\ nedvedova@itam.cas.cz \\ ${ }^{\mathrm{b}}$ Faculty of Economics and Management, Czech University of Life Sciences Prague, Kamýcká 129, 16521 Praha 6; CZ \\ pergl@pef.czu.cz
}

KEY WORDS: Manuscripts, Proceedings, ISPRS Archives, Guidelines for Authors, Styleguide

\begin{abstract}
:
The goal of this paper is to present some of the results of an ongoing project focused on protection of cultural heritage from flood danger. We present an original methodology of risk analysis of movable and immovable cultural heritage and two supporting web applications: one for experts and one for ordinary users. Cultural heritage forms a special category that requires different approach towards risk mitigation than other ordinary objects. First of all their assets cannot be reproduced so we have to pay much more attention for the correct preventive measures as well as remedial works after the potential disaster. Second, historical materials are usually more predispose to damage as they are already eroded by age. This brings a need of profound knowledge of the mechanical, chemical and biological reaction to the flood stress. This knowledge is usually not possessed by the stewards and owners in the sufficient rate. This is probably not even possible, because it encompasses knowledge of various building branches from the view of hydrology, physics, biology, chemistry, geology and others. To be able to perform an effective risk analysis and to choose right effective measures means to know the building and its condition as well as its setting very well. Therefore we want to give users and administrators of the buildings clear guidelines how to examine the objects and what else they might need to be aware of, in order to be ready and prepared.
\end{abstract}

\section{INTRODUCTION}

Flood is a natural phenomenon that cannot be avoided; however, in past years due to climate changes and changes in water management its impact is rapidly growing. During the last 20 years we have experienced many severe flooding events that influenced most of the regions in Czech Republic. According to experience and climatology, it seems that we will go through them more often than it was common in the past. It is not that there weren't any floods before but big dams and other water measures changed the flood regime and protected large areas. So we somehow forgot and we are not used to them anymore. Due to climate changes but also different type of farming and cultivation of fields and forests water regime is changed again and we start experience flooding more often. It is necessary to bring back awareness of potential danger and also possibilities how to protect ourselves.

\section{Challenges of protecting cultural heritage from floods}

In this paper we focus on problem of flooding, risk analysis, repair and preventive measures of historical monuments and artefacts. There has already been done a lot regarding general protection and guidelines for remedial works after flooding but a special approach towards historical objects and their value seems to be underestimated. Cultural heritage forms a special category that usually requires unique and individual approach because its assets cannot be reproduced in contrast to ordinary buildings and objects.
During last floods we experienced a lot of loss and damages on historical buildings and objects. But the harm was caused not only by moist and mud but also by choosing wrong remedial actions. Especially sensitive are all kinds of finishes as stucco, painting etc. that are normally cleared away as first ones to enable drying of principal constructions. Also construction elements like windows, door and all kinds of movable equipment are highly vulnerable. Thus there is a need of providing better education and methods in this field. People in general should be more aware of values and necessity of special approach to protect them. But stress is put on owners, administrators and technicians that deal with the consequences of a disaster.

Past flood experience didn't bring only harm. It brought a lot of practice and knowledge. These assets should be taken into account and used in a positive way. The expert knowledge and experience from previous floods should be systematically recorded and exposed for searching. Owners and administrators of the endangered buildings should be motivated to do a detailed qualified risk analysis. Therefore the idea of guidelines for risk analysis and supporting software tool for collecting information about construction vulnerability was set.

\section{METHODOLOGY}

The main two concerns are:

1. To formulate questions that owners and administrators may need to know.

\footnotetext{
* Corresponding author.
} 
2. How and where they can actually gain this knowledge.

The first point was elaborated by a team of experts that were directly professionally involved in flood risks mitigations and remedied related to recent big floods. These were experts both on movable and unmovable assets covering a vast range of branches: building, physics, hydrogeology, chemistry, biology. Using their expertise, we formulated crucial questions that are necessary to address.

Furter, as we need to share experts' knowledge with buildings administrators, two steps were necessary to achieve the second point (how and where):

1. To formalize the knowledge.

2. To make it accessible using modern information technologies.

The first step was solved by making an ontology of the flood risk domain, which consisted of semantic networks 0 and mind maps [4]. As this topic is beyond the scope of this paper, we do not go into details here. As web applications are today's powerful way how to deliver information effectively to a broad audience, we built web applications to capture the formalized experts' knowledge and make it available to buildings' administrators.

\section{RESULTS}

\section{Guidelines for risk analysis}

In this section we present the crucial questions that are necessary to address when dealing with cultural heritage flood risks.

\section{- What kind of flood might hit the property?}

This question encompasses all possible information about previous flooding in your area - dynamics of the flood, season when it appears, repetition, duration, water height.

- What is the cultural and historical value of the property?

It is crucial to know what kind of values the property represents.

- How is the property situated (in landscape, position towards other buildings, hydrogeological conditions etc.)?

This information refers to how the water can get to the building, as water may come not only from the river.

- What is the technical state of the property?

Buildings that are neglected are much more vulnerable than the one well kept. It is necessary to be aware of already existing damages.

- What are the types of constructions and used materials?

Some constructions and materials are more resistant to flood influence than others. It is important to have a precise knowledge of the building composition to be able to predict the risk. Some constructions and materials may even have secondary impacts on others.

- Other aspects that either worsen or mitigate the risks.
For each of the questions, we formulated textual description of its importance in risk analysis and also what are the possible sources of required data or where to get the professional help. The core of the knowledge then lies in quantified measures and relations between the various cross-domain aspects. This knowledge provides a source of detailed information for owners and administrators about the possible risk of their property. We would like to stress that good risk analysis brings more possibilities for effective preventive measures.

\section{Supporting software tools}

Formalized experts' knowledge is not directly usable by broad audience. Thus we developed supporting software tools that would hide the complexity of the knowledge and provide simple, comprehensible and user-friendly device how to work with this knowledge.

The tools contain necessary expert knowledge that may be used to assess the risk of flood for typical constructions, materials and movable objects that are present in cultural heritage objects such as chateaus, churches, old houses, museums, old factories, etc. These are the questions it is able to give answer for.

- What reaction and what damages may I expect for constructions and movable objects according to their material composition?

- What are the secondary risks that may occur?

- What are possible preventive measures if any?

- What are suitable procedures for saving the impacted object? What are the time limits?

These answers are based on acquaintance of experts from different fields of knowledge, on experiences from previous floods and results from other research projects dealing with this topic. We find it very important to gather all this knowledge in one place and make available for wider audience as we experienced that applying impropriate precautions and acts may even make the damage more severe. The system is open so it may be updated and new information may be added.

The application was developed using standard software engineering approach as discussed by Beck in [1] and it was inspired by Agile methodologies [2]. The architecture is clientserver: the target client application platform is a standard web browser. The server part is developed in the Django web development framework [7]. Persistence is managed by a PostgreSQL database.. The whole solution is hosted on Ubuntu Server machine.

The solution consists of two applications:

- Experts' component. It is a closed-access web application that is designed for experts to directly interact with the knowledge base. Its key features (depending on the rights assigned) are:

- Listing the knowledge base contents.

- Adding new risk analysis items.

- Modifying existing risk analysis items.

- Searching the knowledge base.

- The experts' component may be also used directly by the owners, however, it assumes a certain level of orientation in the area.

- Users' component. This component is dedicated to a broad audience that would like to leverage the knowledge base in a read-only mode in a fancy wizardstyle web application.

The Expert's Component is based on standard Django admin sites [7]. It consists of the following main databases: 
- Analyses of risks of constructions.

- Analyses of risks of movable objects.

- Additional experts' information for users regarding particular topics.

- Lists of tabular values of inputs and outputs used in analyses.

The core databases are the first three. For each item in the list, several main characteristics are shown together with the author of the item and creation and last modified timestamps (Fig. 1).

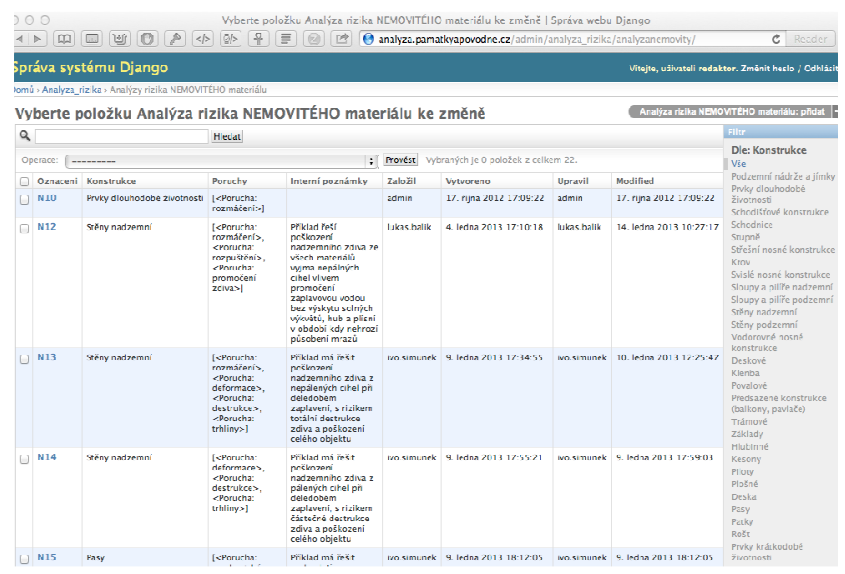

Fig. 1 Knowledge base items in the experts' web application

Users' application is now under construction. So far, the analysis and design has been performed and the implementation is on the go. The sample of the graphic design is in Fig.2.

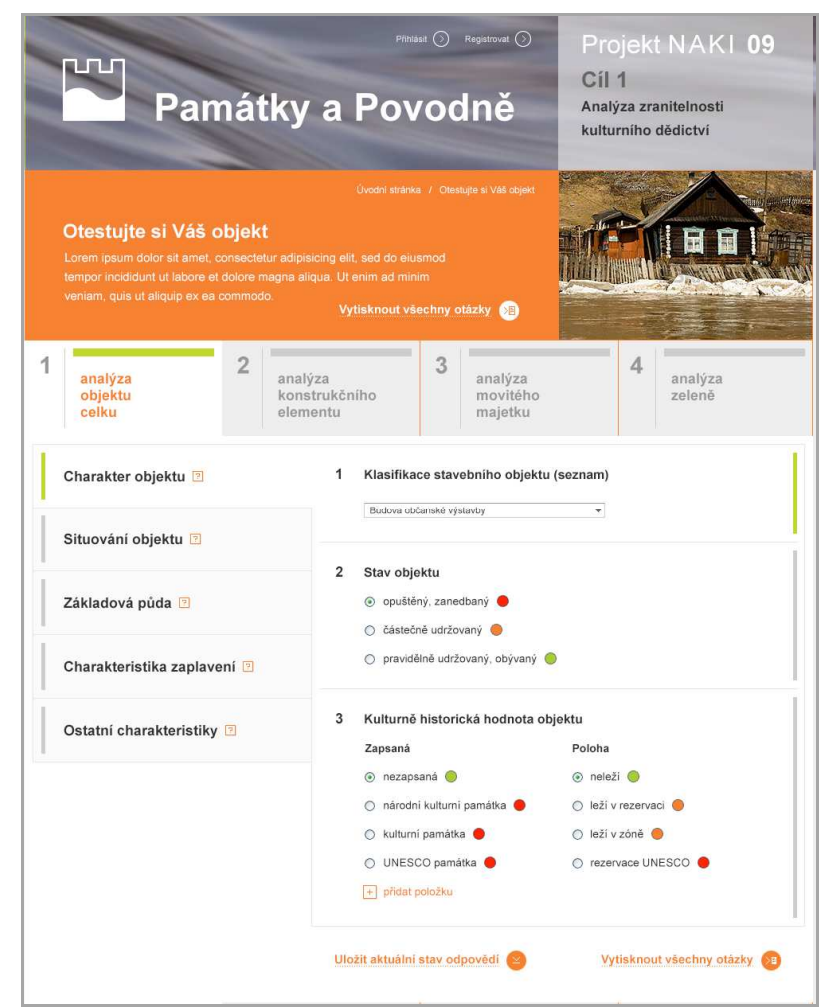

Fig. 2 Design of the users' web application
The application will provide a fancy wizard that will guide the user through the key aspects of flood risk analysis. As such, it will provide a primary interface for buildings' administrators. The complete analysis will consist of:

- Analysis of the building as a whole.

- Individual analyses of constructions in the building.

Based on the provided inputs concerning the building and the characteristics of the expected flood, the report for the user will be generated using the knowledge base. In this report, the risks and recommendations will be presented as described in the Experts' application. Additional comments and recommendations will be provided, too. The user will be also presented with a well-arranged indication of the risk categories in the form of "semaphore lights" and also a brief schedule of necessary rescue procedures.

\section{CONCLUSIONS}

Flood protection is a very actual topic nowadays, though cultural heritage still lies on its outskirt. In our project it showed that cooperation between experts from different domains has to be established to achieve tangible results. Opening up for solving the problem from different points of view seems to be necessary if we want to be effective and successful, particularly in the case of flood protection of cultural heritage. The resulting knowledge software application and methodology guidelines are definitely not perfect nor complete, however our current results open a potential of bringing expert knowledge of flood risk to broader audience. Further development lies in connecting the knowledge base with other information systems like flood maps and generating valuable statistical information from the specific analyses from users.

\section{REFERENCES}

[1] Beck, K. Process Patterns: Building Large-Scale Systems Using Object Technology. Cambridge University Press, 1998.

[2] Beck, K. Extreme Programming Explained - Embrace Change, Addison-Wesley, 2004.

[3] Blasko M., Cacciotti R., Kremen P., Kouba Z. Monument Damage Ontology, Lecture Notes in Computer Science vol. 7616, Series ISSN: 0302-9743, 2012, pp. 221-230.

[4] Buzan, T., Buzan, B. The Mind Map Book. BBC Active, 2006.

[5] Douglas K., Douglas S. PostgreSQL, Sams, 2003.

[6] Drdácký, M., Valach, J., Křemen, P., Abrahamčík, J.: Damage database. In: Cultural Heritage Protection Against Flooding. Prague: Institute of Theoretical and Applied Mechanics Academy of Sciences of the Czech Republic, 2011, p. 185-195. ISBN 978-80-86246-37-6

[7] Holovaty A., Kaplan-Moss A. The Definitive Guide to Django: Web Development Done Right. Apress, 2009.

[8] Houška, M. - Houšková Beránková, M. Semantic Network as a Form of Knowledge Representation and Knowledge Map. Scientia Agriculturae Bohemica, 2008, vol. 39, no. 2, pp. 139 - 147, ISSN 1211-3174.

[9] Pergl, R. Supporting enterprise IS modelling using ontological analysis. Lecture Notes in Business Information Processing, vol. 88 LNBIP, 2011, pp. 130-144.

Sowa, J.F. Semantic Networks, Encyclopedia of Artificial Intelligence. Wiley, 1992. 